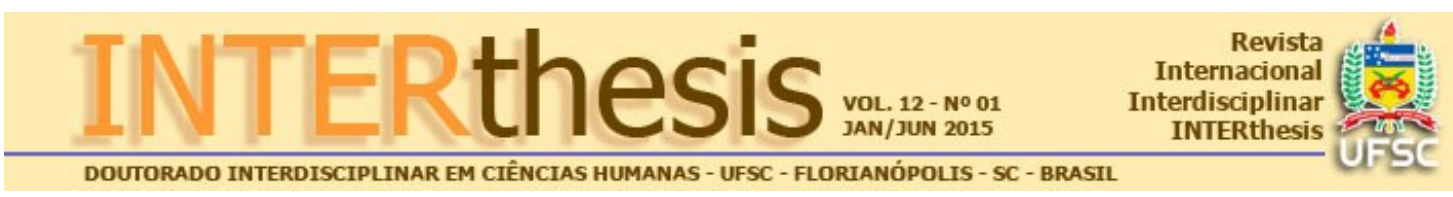

\title{
DIREITOS E CUIDADO PARA A PROTEÇÃO DA AUTONOMIA PRÁTICA DE ANIMAIS NÃO HUMANOS
}

Maria Alice da Silva ${ }^{1}$

Tânia Aparecida Kuhnen²

\section{Resumo:}

O objetivo deste artigo é apresentar o conceito de autonomia prática de Steven Wise e o modo como se distingue da noção tradicional e moderna de autonomia kantiana, buscando evidenciar a importância dessa noção de autonomia para o reconhecimento de direitos jurídicos aos animais não humanos e a proteção de suas formas específicas de vida por meio de práticas de cuidado e de responsabilidade nas relações entre humanos para com não humanos. Por meio da investigação bibliográfica e análise teórica, busca-se, inicialmente, apresentar as distinções conceituais centrais de Wise para, na sequência, indicar a aplicação do conceito de autonomia prática no âmbito jurídico, tendo em vista o reconhecimento de direitos aos animais. Por fim, mostra-se como o conceito de autonomia prática requer mais do que direitos jurídicos. Ele implica obrigações morais por parte de agentes individuais e do Estado para assegurar as condições adequadas de autonomia e liberdade de animais não humanos.

Palavras-chave: Animais não humanos. Autonomia. Cuidado. Direitos. Liberdade.

\section{INTRODUÇÃO}

O debate das últimas décadas em torno dos direitos animais vem desenvolvendo e ampliando o vocabulário jurídico e algumas noções tradicionais comprometidas com o momento histórico na qual foram desenvolvidas. Esse é o caso do conceito de "igualdade". Peter Singer, ao apresentar o princípio da igual consideração de interesses semelhantes, afirma que o conceito de igualdade não refere uma igualdade de fato, mas uma igualdade baseada no compartilhamento de certos interesses semelhantes, tais como, o interesse em manter-se vivo e em não sentir dor. Não é o formato externo do indivíduo, nem alguma propriedade ou

1 Doutoranda no Programa de Pós-graduação em Filosofia da Universidade Federal de Santa Catarina. Pesquisadora bolsista da Fundação de Amparo à Pesquisa e Inovação do Estado de Santa Catarina (FAPESC), Florianópolis, SC, Brasil. E-mail: mariaalicesilv@gmail.com

${ }^{2}$ Doutora em Filosofia pela Universidade Federal de Santa Catarina. Realizou estágio de pesquisa na Humboldt Universität zu Berlin, Florianópolis, SC, Brasil. Email: taniakuhnen@hotmail.com 
aptidão aparente que conta para sua igualdade, mas sim seus interesses. O que acreditamos mesmo quando defendemos a igualdade é que compartilhamos todos os interesses, que devem ser respeitados e atendidos. O princípio moral exige, segundo Singer (1994, p. 30-31), que se atribua o mesmo peso aos interesses que se apresentam como semelhantes, independentemente de qual for o ser em questão ou de quem for o interesse. Por meio dessa concepção de igualdade, Singer a expande para além da fronteira da espécie humana e consegue garantir proteção moral a todos os seres sencientes dotados de interesses semelhantes.

Também a noção de "autonomia" e suas implicações no sentido tradicional do termo tem sofrido questionamentos e reformulações. Tomada em seu sentido tradicional, dificilmente há como aplicar a noção de autonomia aos animais, uma vez que tal característica foi pensada em certo período histórico justamente para distinguir seres humanos dos demais animais, e atribuir aos primeiros um estatuto diferenciado. Por serem autônomos, seres humanos foram então reconhecidos como superiores aos membros de outras espécies e, por isso, dignos de integrarem a comunidade moral e serem beneficiários da proteção jurídica, bem como terem outras vantagens legais e ganhos sociais. Com o novo cenário das discussões sobre os direitos animais, o conceito de autonomia vem, portanto, passando por reformulações tendo em vista atender ao interesse de expansão da comunidade moral para além de seres humanos.

Ainda que alguns eticistas animalistas, a exemplo do que faz Peter Singer, dispensem a noção de autonomia por estar comprometida com a ética tradicional e sigam outras vias de argumentação a favor da inclusão dos animais sencientes na comunidade moral, centrada no respeito aos seus interesses e preferências, esse conceito mantém-se central para autores que defendem a atribuição de direitos aos animais. Enquanto o conceito de igualdade é central para Singer, uma vez que ele reivindica a inclusão dos seres sencientes dentro da comunidade moral, a noção de pessoa é central para aqueles que buscam reconhecer direitos jurídicos aos animais não humanos. Outros autores defendem os direitos jurídicos aos animais, é o caso, por exemplo, de Gary Francione.

Francione considera que há pelo menos um direito que é essencial para todos os seres sencientes: o direito a não se constituir como propriedade. Para defender este direito é preciso sanar nossa esquizofrenia moral. Este conceito, o de 
"esquizofrenia" deixa evidente a percepção dos animais no mundo jurídico. Os animais, atualmente, são coisas legais, ou seja, propriedades do estado. Todavia, reconhecemos que, diferente da flora, os animais sentem dor e por isso, temos o dever de não sermos cruéis com eles. O dever de proteção de um lado e as leis que regulamentam a exploração animal são provas da nossa esquizofrenia. Consideramos que os animais são coisas e que são seres necessitados de cuidados. A única maneira de sanarmos tal contradição é atribuirmos direitos aos animais, direitos básicos como pessoa jurídica.

A justificativa de Francione para incluir os animais no escopo de pessoas jurídicas, é, pois, reconhecemos neles os mesmos atributos que evidenciamos em outras pessoas: senciência. Isto faz com que os humanos e não humanos sejam semelhantes e possa desfrutar do mesmo mecanismo de proteção, o Direito (FRANCIONE, 2013, p29). Para Francione, ao acrescentarmos o princípio de igual consideração, princípio este que os sistemas jurídicos, em sua imensa maioria dos casos já utilizam, percebemos que tratamos os animais de maneira dessemelhante ao possuírem características iguais às outras pessoas jurídicas.

Outro autor que discute o conceito de pessoa jurídica e utiliza do mesmo modo o princípio de igual consideração é Steven Wise, tendo em vista sua aplicação aos animais não humanos. Wise procura superar a noção kantiana de autonomia por considerá-la significativamente excludente, uma vez que se o sistema jurídico trabalhasse de forma coerente com esse conceito, deixaria de fora todos os humanos sem a capacidade de reconhecer as leis morais universais. Uma nova linha precisa, então, ser desenhada para incluir de maneira adequada e proporcional às suas capacidades práticas e não morais outros sujeitos de direitos. Nesse sentido, tem-se que a autonomia que importa ao direito, tendo em vista a inclusão dos animais, é a prática e não a racional. Precisamos saber se os animais não humanos são capazes de se mover, sentir, escolher um ambiente adequado para si, selecionar seus alimentos, optar por fazer umas ações em detrimento de outras, desenvolver certas emoções e outras características importantes para seres vivos. Considerando essas habilidades, animais precisam ter sua liberdade assegurada em termos jurídicos analogamente aos humanos que possuem tais habilidades.

Tendo em vista a contribuição teórica para a reestruturação da noção de autonomia, o objetivo deste artigo é apresentar o conceito de autonomia prática de 
Steven Wise em seu livro, Drawing the line, e salientar sua distinção da noção tradicional e moderna de autonomia kantiana. Isso se faz necessário para justificar o reconhecimento de direitos jurídicos aos animais não humanos ao se concebê-los como componentes do direito civil. Também a proteção de suas formas específicas de vida por meio de práticas de cuidado e de responsabilidade nas relações entre humanos para com não humanos, para além de direitos positivados, pressupõe o respeito a uma noção de autonomia e de liberdade por parte dos animais.

Ao longo deste artigo, por meio da investigação bibliográfica e analítica, apresentamos primeiramente as distinções conceituais centrais de Steven Wise, salintando-se o uso do conceito de autonomia prática para o reconhecimento de direitos aos animais. Por fim, procura-se mostrar que as implicações do conceito de autonomia prática vão além da atribuição de direitos jurídicos. Tal conceito implica obrigações morais por parte de agentes individuais e do Estado para assegurar as condições adequadas para o exercício da autonomia e da liberdade por parte de animais não humanos.

\section{O CONCEITO DE AUTONOMIA PRÁTICA E A LIBERDADE DE ANIMAIS EM WISE}

Em seu livro, Fundamentação da metafísica dos costumes, Kant iniciou uma tradição que coloca o conceito de autonomia no centro das discussões sobre os agentes e os considerados moralmente, isto é, os que possuem dignidade e estão aptos a integrar a comunidade moral. Com isso, a pessoa detentora de autonomia moral, e possuidora da razão, não é só aquela que julga moralmente, mas, aquela que deve ser considerada moralmente nas ações dos outros agentes. $O$ modelo teórico kantiano tornou-se o de maior alcance dentro da filosofia moral ocidental, reconhecendo, então, todos os seres racionais como capazes de exercer sua autonomia e liberdade na aplicação do imperativo categórico. Somente o ser racional, na condição de agente moral, pode inferir o princípio supremo da moralidade como aquele que expressa o dever e o moralmente correto, o que, por sua vez, seria uma manifestação de sua própria autonomia.

A autonomia em Kant compreende a capacidade racional de auto-imposição de leis, isto é, de pensar máximas subjetivas ou regras que possam ser 
universalizadas e transformadas em leis universais a serem seguidas por todos os seres racionais. Tal concepção encontra-se expressa em uma das formulações do imperativo categórico: "nunca praticar uma ação senão em acordo com uma máxima que se saiba poder ser uma lei universal, quer dizer só de tal maneira que a vontade pela sua máxima se possa considerar a si mesma ao mesmo tempo como legisladora universal" (KANT, 1986, p. 76). A ideia central aqui que o ser racional submeter-se à somente as máximas que, ao mesmo tempo, podem ser adotadas e seguidas por todos. O ser que age segundo uma máxima que não pode ser universalizada, também não está exercendo nem sua autonomia, nem sua vontade racional e livre e, portanto, deixa mesmo de ser livre. Isso, por sua vez, implica abrir mão da própria dignidade, pois o ser racional digno "não obedece a outra lei senão àquela que ele mesmo simultaneamente dá" (KANT, 1986, p. 77).

O conceito de autonomia também é importante para Steven Wise. Todavia, seus escritos denunciam o conceito limitado de "autonomia moral" kantiana que vinha sendo utilizado até então de forma preponderante na filosofia moral. Para Wise, tal conceito enfrenta limitações, pois, não explica como incluímos no escopo moral ou jurídico humanos sem a capacidade de derivar leis morais. Para Wise, o sistema jurídico não pode trabalhar com esse conceito de autonomia, e de fato, não trabalha. Exemplos disso são as ficções jurídicas, como instituições e as potencialidades, como os embriões e bebês, ambos são possuidores de direitos e não possuem autonomia moral.

Para kant apenas são dignos aqueles humanos que podem reconhecer e respeitar as leis morais, e isto fundamenta, em sua teoria, o dever de respeito pelos humanos, assim os tornam dignos de serem considerados moralmente e sujeitos de direitos. Todavia, estes humanos correspondem uma pequena porção dos humanos protegidos por lei. Estes são os humanos autônomos por completo, que correspondem ao mais alto nível das capacidades cognitivas (WISE, 2002, p 31). Todavia, esta ideia implica em tirar do escopo de seres dignos alguns humanos, como bebês, crianças e outros não capazes de agir da maneira racional como pressuposta por Kant. Pois para ele, seres autônomos são capazes de derivar as leis morais do imperativo categórico e agir de acordo com sua livre vontade. "Os animais não-humanos também não podem agir de acordo com este conceito de 
autonomia e liberdade por completo tal qual definido por Kant” (WISE, 2002, p30. Tradução nossa).

Assim, Wise propõe pensarmos no conceito de "autonomia prática" em substituição ao de autonomia tradicional no sentido kantiano do termo. Pois, o conceito de autonomia possui níveis, e o ato de derivar leis morais é o máximo grau, excluindo outros seres, inclusive humanos, que possuem outras habilidades importantes para viverem são excluídos da teoria kantiana. Em concordância com Wise, um dos motivos que apresentamos para a mudança do conceito de autonomia utiliza-se do exemplo de pessoas jurídicas e consideradas eticamente que não são possuidoras de tal característica. Este é o caso de crianças, idosos, humanos em estado vegetativo ou terminal ou deficientes mentais que jamais foram capazes de escolha racional. Em seu livro, Drawing the Line (2002), Wise apresenta o conceito de autonomia prática como referindo a capacidade que outros seres para além dos humanos possuem de fazer escolhas livres. Para o autor, esse deve então ser o critério para a linha divisória e a inclusão no âmbito de atribuição de personalidade jurídica, bem como de reconhecimento dos seres como moralmente relevantes.

Acerca da gênese do conceito de autonomia prática em Wise e da importância desse conceito para justificar o valor moral direto da vida de animais não humanos, Felipe salienta:

\begin{abstract}
Em seu primeiro livro, Rattling the cage (2000), Steven M. Wise usa a expressão "autonomia realista" para designar tais habilidades animais. Em Drawing the line (2002), entretanto, o autor adota o conceito de "autonomia prática", substituindo o de "autonomia realista", com a mesma intenção da definição anterior, qual seja, a de sustentar filosoficamente a defesa de liberdades físicas para tais animais, a exemplo do que se assegura hoje a seres humanos não dotados de autonomia moral, mas aptos ao gozo de liberdades relacionadas à autonomia prática: o não impedimento físico para atender a preferências individuais que respeitam o próprio bem-estar, garantido de forma proporcional à capacidade individual de usar essa liberdade física sem colocar em risco sua integridade e a dos demais seres vivos (FELIPE, 2007, p. 283).
\end{abstract}

Conforme se pode notar, Felipe aponta para a importância da ampliação do conceito de autonomia com o fim de apagar a linha divisória que separa humanos de outros seres vivos capazes de senciência, preferências e interesses. Tal ampliação possibilita garantir direitos jurídicos e morais aos seres que possuem natureza mental desconhecida ou diferente da nossa, uma vez que são possuidores de outro tipo de autonomia também compartilhada por muitos seres humanos de capacidades restritas, qual seja, a autonomia prática.

R. Inter. Interdisc. INTERthesis, Florianópolis, v.12, n.1, p.42-64, Jan-Jun. 2015 
Felipe também salienta as características dos possuidores dessa modalidade amplificada de autonomia:

\begin{abstract}
Sensibilidade, consciência, percepção de si (self), desejo e intenção constituem alguns indícios ou evidências de que os animais têm autonomia prática. Tais indícios podem ser observados através de comportamentos que resultam de atividade mental, ainda que em alguns casos essa pareça ser mínima. Observação, atenção, memória e coordenação mental do próprio movimento no ambiente natural são habilidades constitutivas dos animais capazes de fazer escolhas, nos quais Wise reconhece a autonomia prática e em relação aos quais propõe a proteção constitucional das duas liberdades vinculadas ao gozo dessa autonomia: o não-aprisionamento e a possibilidade do movimento para autoprover-se e prover os dependentes (FELIPE, 2007, p. 28).
\end{abstract}

A partir do exposto, torna-se claro que a noção de autonomia prática é significativamente mais abrangente, elevando de forma coerente o status, inclusive, de muitos seres humanos que durante toda a sua vida ou, pelo menos, durante uma etapa dela, não satisfazem as condições da noção tradicional de autonomia kantiana, denominada por Wise de autonomia realista. Mas além da expansão da noção de considerabilidade moral derivada dessa noção de autonomia, Wise passa então a argumentar a favor do reconhecimento de certos direitos aos animais não humanos e sua inclusão sob a proteção constitucional.

Liberdade prática é a capacidade que um ser tem de ter vontade e mover-se para atender sua vontade (WISE, 2002, p. 36-37). Com isso, Wise descreve que animais outros, que não só os humanos possuem a capacidade de escolha. Capacidade esta que é o importante para vivermos em sociedade e manter suas próprias necessidades e dos outros em sua volta. Os humanos possuidores destas características, e outras pessoas jurídicas que são ficções (o caso de uma instituição ou empresa) já são contemplados pelo sistema jurídico, assim, os animais não humanos também devem ser protegidos pelo sistema e colherem benefícios dele.

Alguns animais possuem habilidades tão complexas e próximas às habilidades de humanos adultos que, torna-se evidente sua autonomia. Os grandes primatas, os golfinhos, os papagaios e os elefantes possuem não só emoções, mas, possuem capacidade de reconhecer-se, desejar objetos e compreender como seus, e cuidar de outros. Estes animais possuem a noção de "me-self" e de "i-self", fazem abstrações cognitivas muito complexas, desenvolvem linguagem e elaboram ideias. Mas, "de acordo com o sistema jurídico atual estes seres não são dignos de direitos básicos" (WISE, 2002, p 157). Essa afirmação salienta a necessidade de pensarmos 
os direitos através da lente de seu conceito de autonomia prática, pois, este conceito que permite enxergar as habilidades de outras espécies.

Ao reconstituir a argumentação de Wise, Felipe salienta:

Todo ser vivo, dotado de autonomia prática, deve ser investido de personalidade jurídica e dos direitos básicos da liberdade. De um animal se pode dizer que é autônomo, assim o entende Wise, sempre que for possível constatar que: 1) tem desejos; 2) tenta, intencionalmente, satisfazer esses desejos; 3) possui "um sentido de si, por mínimo que seja que lhe faculta a clareza de que o desejo é seu, do mesmo modo que são seus os esforços para tentar conseguir o que deseja". Tais critérios estabelecem direitos relativos à dignidade da vida animal, conforme o denomina Wise (FELIPE, 2007, p. 28).

Importa salientar que de forma análoga aos seres humanos, animais não humanos são diferentes um dos outros e cada um possui uma habilidade particular para conseguir satisfazer suas vontades, interesses, desejos e preferências. Alguns animais, além disso, são conscientes de si, podem se reconhecer, podem ver a si mesmos e saber algo sobre si. "Isso significa que eles compreendem símbolos, usam um sofisticado sistema de linguagem ou algo similar, são capazes de disfarçar, representar, imitar e resolver problemas complexos" (WISE apud FELIPE, 2007, p 283).

Os estudos em biologia têm também salientado certas habilidades de animais não humanos, a exemplo da capacidade para a empatia e simpatia presente em determinadas espécies animais, cujos indivíduos distinguem-se por perceberem a situação do outro e colocarem-se no lugar dele. Frans de Waal, em The Age of Empathy, investiga e fornece evidências dessa habilidade nos primatas superiores, que possuem, inclusive, um senso de vivência em comunidade, a preocupação com outros indivíduos do mesmo grupo e, por isso, procuram "melhorar o estado de relações em um grupo como um todo" (DE WAAL, 2009, p. 37).

A natureza empática e simpática de tais seres, que os permite assumir a perspectiva de outro, é uma indicação da consciência desenvolvida nesses animais que, do mesmo modo que a maior parte dos seres humanos, possuem habilidades distintivas e complexas. Devem, portanto, estar na categoria de animais conscientes e possuírem certos direitos iguais aos de seres humanos com níveis similares de consciência.

Animais conscientes, diferente de outros animais que são apenas sencientes, podem ter insights, podem pensar e resolver problemas com eficiência e segurança. 
Esses animais fazem escolhas, mostram que suas habilidades são maiores do que as habilidades de outros animais. As escolhas feitas por estes animais possuem finalidades, e não são movimentos mecânicos ou instintos. (WISE, 2002, p. 36). Eles representam a prova da autonomia prática, pois, conseguem exercer outras habilidades sofisticadas, semelhantes às habilidades que exigimos de humanos, por exemplo, calcular, elaborar linguagem, ter pensamento. Por isso, para que os animais sejam reconhecidos de maneira diferente das árvores, montanhas e rios é preciso que sejam reconhecidos de maneira efetiva dentro do sistema. Os animais precisam estar no nível de proteção dos humanos, e deixarem de serem comparados à proteção limitada da flora. Esta virada só é possível quando considerarmos a autonomia prática, aquelas habilidades de escolhas como mais importantes do que às habilidades de autonomia moral. Uma vez que os animais possuem liberdade prática (ou autonomia prática) por que então não reconhecê-los como dotados de direitos fundamentais da mesma forma que seres humanos? Além disso, se o sistema jurídico trabalha com conceitos de potencialidades e ficção jurídica, por exemplo, no caso de humanos não nascidos, qual a razão de deixar de lado esses conceitos no caso de animais não humanos? Wise assim esclarece em relação a essa questão:

\begin{abstract}
Julgamos sem personalidade [jurídica] alguns animais não-humanos de maneira arbitrária. Mas, não parecemos fazer isso em todos os casos. Não achamos arbitrário trabalhar com o conceito de ficção jurídica. Ficções jurídicas são mentiras que nós insistimos em acreditar. Assim, atribuímos personalidade não apenas a humanos sem consciência, mas fazemos isso também com corporações e ídolos religiosos. Eles pretendem ser entidades que gozam de autonomia (WISE, 2002, p. 30).
\end{abstract}

Apesar de reconhecer que certos conceitos são ficções, Wise não descarta a relevância dessas ficções jurídicas. O que ele faz, na verdade, é questionar a incoerência em fazer uso de tais ficções para o benefício dos seres humanos, ao mesmo tempo em que se as nega para reconhecer o valor moral de animais não humanos, limitando o reconhecimento de direitos aos membros da espécie. No entender de Wise (2002, p. 31), ao considerar a autonomia moral, ou seja, a capacidade de discernir moralmente suas escolhas, como o pressuposto para dar direitos aos humanos, exclui-se também humanos, como é caso de crianças e daqueles que nascem de forma definitiva sem essa capacidade. Assim, tão melhor e coerente seria inserir o conceito de especismo e sanar o problema da incoerência de 
dar direitos aos membros de uma espécie que não possuem a característica desejada para possuir direitos jurídicos. A barreira da espécie é a única coisa que impede de dar a mesma proporção aos seres humanos e não-humanos. Além disso, ao se negar aos animais o reconhecimento da proteção jurídica, não se reconhece que, conforme bem pontua Felipe (2007, p. 286), "a mente humana também é limitada, necessitando décadas para aprimorar-se, e ainda assim, direitos fundamentais são garantidos a todas as crianças e adolescentes".

Para um sistema jurídico ser justo e equitativo, afirma Wise (2002, p. 32), deve-se investir de personalidade jurídica todo ser vivo capaz de autonomia prática mínima e, por conseguinte, conferir-Ihes os direitos básicos da liberdade. Em relação a isso, Felipe acrescenta:

Ao se atribuir aos animais liberdades físicas proporcionais à sua autonomia
prática, segue-se o mesmo critério, o de preservar a segurança individual e
coletiva, adotado ao se conceder liberdades físicas a humanos. Limitar a
liberdade dos animais, quando representam ameaça aos demais seres
vivos, não deve ser considerado um ato especista. Humanos também têm
sua liberdade limitada quando não podem responder plenamente por seus
atos. Nesse sentido, a proporcionalidade da liberdade física, concedida a
um animal não-humano, deve ter em vista a capacidade desse animal para
mover-se em liberdade para autoprover-se, com garantia de que não ponha
sua saúde e integridade em risco, nem ameace a dos demais. Com base
nesse entendimento, percebe-se por que Wise classifica a autonomia
prática do cão num nível inferior ao dos outros animais, ao dos elefantes,
por exemplo. A liberdade física do animal deve ser garantida
proporcionalmente à sua capacidade para viver com qualidade em seu
habitat, sem colocar em risco o bem-estar de sua vida ou o de outros
(FELIPE, 2007, p. 287).

Com o conceito de autonomia prática gera-se a preocupação de saber o que cada animal, seja ele humano ou não-humano, precisa para viver bem e exercer suas potencialidades de forma plena. Assegurar certos direitos aos animais, como os de liberdades básicas, é uma expressão desse tipo de preocupação prática em atender necessidades e preferências individuais. O sistema jurídico junto com políticas públicas e com o poder estatal precisa atender a essa e outras demandas. Essa é uma das vantagens em ser titular de direitos. Os animais não são seres com obstruções mentais, pelo contrário, são indivíduos autônomos, mas, cada qual exercendo sua autonomia prática a seu próprio modo. Alguns mais próximos dos humanos, outros menos. Todavia, pouco isso importa, visto que cada um deve ter o que necessita de acordo com as exigências de sua liberdade prática. 


\section{A CLASSIFICAÇÃO DOS TIPOS DE AUTONOMIA}

Uma vez ampliado o sentido de autonomia, agora ligada a capacidade prática de se mover em conformidade com a vontade própria para assegurar seu provimento, Wise preocupa-se em oferecer uma classificação dos animais numa escala de gradação de autonomia prática. Com isso, visa oferecer um instrumento para que se possa atender de forma mais adequada às necessidades, desejos e interesses de animais não humanos.

No momento em que o sistema jurídico aplicar a classificação de Wise, deve levar em conta a capacidade conhecida de cada animal. Na classificação elaborada pelo autor, há um espaço para o respeito à limitação das informações sobre a especificidade de cada espécie. Não há nenhuma premissa que impeça os animais de mudarem de categoria, caso alguma habilidade nova torne-se conhecida pelos humanos. Infelizmente, permanece essa limitação ao construir a linha das liberdades práticas. Todavia, o intuito de tornar nossa relação com os não-humanos mais justa é o que incentiva e torna possível mais estudos e mais conhecimento sobre as particularidades de animais em termos de autonomia e liberdade prática.

Wise apresenta, então, um gráfico que classifica os mais diversos animais de acordo com sua autonomia prática e as características citadas no item anterior deste artigo. Os valores vão numa escala de 0.0 a 1.0 de acordo com o conhecimento científico disponível no momento. O desenho da escala pode mudar em conformidade com os novos saberes científicos acrescidos. Por isso, a escala não constitui uma forma estática e definitiva de classificação da autonomia de animais; ao contrário, está aberta a constante revisão e evolução das pesquisas científicas sobre as habilidades de animais não humanos. Ao elaborar a tabela, Wise (2002, p. 241) leva em conta diferentes espécies animais, tais quais: elefantes, golfinhos, baleias, papagaios, abelhas, cães, bonobos, entre outros.

Felipe descreve essa tabela de forma explícita, sustentando que "quanto mais combinadas estiverem essas habilidades umas com as outras em um determinado indivíduo, mais elevado o nível de autonomia prática que lhe deve ser reconhecido, 
portanto, mais liberdades the devem ser garantidas por lei."(FELIPE, 2007, p. 292293). A categorização de Wise é assim apresentada por Felipe:

\begin{abstract}
A categoria 4 , de 0.0 a 0.49 na escala de Wise, abrange os animais que, pelos dados científicos atuais, possuem reduzidíssimas habilidades mentais. Nessa categoria são classificados animais não-humanos que evidenciam a ausência de autonomia, pelo menos naquele nível, considerado pelo jurista sucificiente para o gozo dos direitos básicos de liberdade.

A categoria 3 , de 0.50 a 0.70 , abrange animais a respeito das quais não dispomos informações que nos autorizem afirmar com propriedade que possuem suficiente autonomia para direitos básicos da liberdade. Nessa categoria deve-se incluir a maioria das espécies, entre elas, a das abelhas e cães, não porque sejam limitados de autonomia prática, e sim por não sabermos como garantir-lhe a liberdade física.

À categoria 2, de 0.70 a 0.90 na escala, Wise destina animais que possuem suficiente autonomia para os direitos básicos da liberdade. Mesmo classificado no limite extremo inferior dessa categoria, deve ter sua liberdade garantida [...].

A categoria 1, com graus que variam de 0.90 a 1.00 , inclui animais nãohumanos que possuem suficiente autonomia para os direitos básicos da liberdade [...]. Golfinhos do Atlântico (0.90), orangotangos (0.93), gorilas (0.95), bonobos (0.98) e humanos (1.00) (FELIPE, 2007, p. 293-294).
\end{abstract}

Tendo por base essa classificação, há razões fortes e suficientes para superar os limites entre os animais e os humanos, bem como para aceitar a defesa de direitos efetivos, ou seja, de maneira que haja direitos positivos por meio dos quais o sujeito pode agir no âmbito do direito, seja por si mesmo, seja por representação no caso dos incapazes. Wise usa a nomenclatura "tutela"/ "representante" [guardianship] de maneira recorrente. Certamente, Wise não defende que os animais devem votar, estabelecer contratos e outros artifícios que apenas humanos adultos com capacidade de escolha para tais objetivos são capazes. O que se pretende, conforme se infere da tabela de classificação, é oferecer a cada espécie o que ela precisa para bem aproveitar suas capacidades de mover-se, prover-se e auto preservar-se. O Estado e o Direito, nesse sentido, precisam incluir esses animais como sujeitos possuidores de benefícios para que possam gozar de dispositivos que ficções e potencialidades garantem aos seres humanos. É o caso de ficções e potencialidades jurídicas: embriões, empresas, crianças, humanos adultos com problemas mentais, humanos em fase terminal. Todos estes exemplos não possuem o mais alto grau de autonomia, não são seres aptos para exercer a autonomia moral, mas, possuem outras habilidades reconhecidas como importantes pelo Direito, e por isso, são pessoas jurídicas com direitos. 
É importante destacar que nos referimos frequentemente às expressões "seres capazes de escolha" ou "humanos capazes de escolhas". Isso se faz necessário, sobretudo, após a definição de autonomia (e liberdade) prática. Quando aludimos a liberdade de alguém, seja de um humano ou de um não-humano, precisamos salientar que tipo de liberdade esse animal possui. Humanos adultos saudáveis possuem uma liberdade de escolha muito mais complexa e extensa do que a de bebês humanos. De forma análoga, primatas possuem uma liberdade prática maior que cães, ou ao menos é o que sabemos hoje. Com isso, torna-se adequado ao conceito de "liberdade prática" nomear o indivíduo que estamos nos referindo, para então, supormos que tipo de habilidade está em jogo. Caso não façamos essa explicitação, não temos a quebra da tradição kantiana e não rompemos com a limitação de seu escopo de dignidade e consideração moral àqueles que são agentes morais. A ruptura precisa ser feita, pois a questão da autonomia é melhor pensada quando as características que incluem os considerados pelo agente (moral ou jurídico) correspondem às seguintes: capacidade de sofrimento, de escolha e movimento e vulnerabilidade. Caso contrário, como em Kant, temos que criar mecanismos para incluir em nosso escopo de consideração os humanos que não possuem autonomia moral.

A passagem que fundamenta a inclusão dos animais no sistema jurídico a partir da sua característica detentora de liberdade prática é a aplicação do princípio de igual consideração. Princípio este que é usado no sistema jurídico como a aplicação da justiça: tratar os iguais de maneira semelhante. Assim, se o sistema jurídico insere em seu escopo de pessoas jurídicas seres com características que poderiam ser descritas pelo conceito de Wise, deve fazer o mesmo com outros portadores da mesma habilidade. Assim, o argumento é jurídico, é positivista. Por isso, o princípio de igual consideração é importante para a teoria de Wise, assim como o princípio de proporcionalidade. Este último defendido por Wise para aplicar junto aos graus de sua tabela que classifica os níveis de autonomia prática (WISE, 2002, p 239).

Estes dois princípios, grosso modo, geram esta máxima: devemos tratar todos os seres que possuem a mesma habilidade da mesma forma e proporção. A proporção deve ser guiada pelos critérios da tabela e o conteúdo da igualdade dependeria das leis de proteção e dos direitos e garantias de cada sistema jurídico. 
Mas, independente das garantias e políticas oferecidas em cada sistema jurídico, o direito de proteção e de não ser violentado deve, necessariamente ser atribuindo a todos os animais sencientes. Outros tipos de garantias devem ser calculados de acordo com a habilidade de cada animal.

O princípio da igual consideração é o mesmo usado por outros filósofos e abolicionistas, como Peter Singer e Gary Francione, Felipe arremata: "Ao se atribuir aos animais liberdades físicas proporcionais à sua autonomia prática, segue-se o mesmo critério, o de preservar a segurança individual e coletiva, adotando ao se conceber liberdade física a humanos" (FELIPE, 2007, p 287). Os princípios determinam juntos, tratar com igualdade os casos iguais de maneira semelhança e diferente que possui características diferentes. Do mesmo modo entre todas as espécies.

Um sistema jurídico não especista respeita a liberdade prática de todos os animais, e para isso, não pode atribuir aos animais o status de "coisa" e "propriedade". A vantagem prática, e não só de justiça, em atribuir tais direitos aos animais, seria de atribuir tutela legal. Com isso, os tutores poderiam mover ações civis a seu favor, respondendo juridicamente por eles, e não dependeriam de defesa do ministério ou e ONGs. Outro benefício é possuir ações de política pública a fim de oportunizar o exercício de suas liberdades, e não apenas leis criminais. Apesar de existir leis que proíbem a crueldade animal, esta regulamenta uma série de outras leis exploratórias. Precisamos romper as barreiras do direito penal e adentrar no âmbito civil para a real defesa dos animais.

Ao reconhecer liberdades práticas que são proporcionalmente iguais às liberdades de outros humanos, o sistema jurídico precisa se comprometer com a justiça em aplicar os mesmos casos com igualdade, isto é, o princípio de igual consideração, sem a barreira da espécie e com o critério da autonomia e liberdade prática, a fim de oferecer reais garantias para os seres que necessitam delas.

As garantias que a teoria de Wise trás como consequência de sua conceptualização é de um abolicionismo além do "não matar! Não maltratar! Não aprisionar" é preciso dar-lhes tudo o que for preciso para viver bem, para exercer bem sua natureza e para cuidar de suas capacidades próprias. 


\section{A PROTEÇÃO DOS ANIMAIS NÃO-HUMANOS PARA ALÉM DOS DIREITOS JURÍDICOS}

Para além da proteção assegurada aos animais não-humanos por meio do reconhecimento de seu estatuto jurídico, os indivíduos e a sociedade precisam conceder-lhes também ações e políticas que visem garantir as melhoras condições para a realização de suas vidas, de acordo com as especificidades de suas formas de vida condizentes à espécie a que pertencem. Essa é uma das implicações do conceito de autonomia prática. Em outras palavras, para que animais não humanos tenham as condições ideais para o exercício de sua autonomia prática, é preciso ir além dos direitos assegurados em um sistema jurídico. Isso implica obrigações morais por parte de agentes individuais e do Estado que se estendem para além de direitos positivados.

Entendemos, portanto, que a autonomia prática não justifica apenas a inclusão de animais no âmbito dos direitos jurídicos, mas também no contexto de políticas públicas sociais. Por isso, ação do Estado tem de ter em vista o bem próprio de cada animal individual. O conceito de "bem próprio" é uma contribuição teórica de Paul Taylor na obra, Respect for Nature, e afirma que cada animal tem uma forma que lhe é própria de realizar sua vida. Os seres vivos, humanos e não humanos, possuem uma forma singular de se auto-realizarem, ou seja, são fins em si mesmos no sentido de que são centros teleológicos de vida e devem ter sua vida respeitada, bem como as devidas condições asseguradas para que realizem sua vida da melhor forma. A singularidade de cada ser vivo não permite nenhuma hierarquização de valores em vista de algum suposto fim humano supremo da moralidade, sendo independente de qualquer outro "fim de algum ser consciente", ou da "realização do bem de algum outro ser, humano ou não-humano, consciente ou não-consciente (TAYLOR, 1989, p. 75). É função então de agentes morais individuais, bem como do próprio Estado, por meio de políticas públicas, garantir que animais não humanos, de forma análoga aos seres humanos, possam realizar seu bem próprio. Isso inclui, por exemplo, redes de proteção e cuidado contra infortúnios e intempéries.

R. Inter. Interdisc. INTERthesis, Florianópolis, v.12, n.1, p.42-64, Jan-Jun. 2015 
Taylor acrescenta que por terem um bem próprio, cabe atribuir as entidades vivas um bem inerente [inherent worth], o qual, por sua vez, implica dois julgamentos morais: 1) que o ser merece a preocupação e a consideração moral, sendo considerado um sujeito à moralidade; 2) que os agentes morais possuem um dever prima facie de promover e preservar o bem do animal como um fim em si e tendo em vista o interesse do animal cujo bem está em questão (TAYLOR, 1989, p. 75). Nossas relações para com esses animais vão além, portanto, das exigências impostas pelo ordenamento jurídico e implicam um tipo de relação moral que nos leva a reconhecer uma reivindicação de respeito que, por sua vez, é derivada da condição de se constituírem em centros teleológicos de vida.

Ao se considerar de forma séria a noção de autonomia prática, tem-se que é dever do Estado ultrapassar a proteção estritamente legal, que visa muito mais evitar danos diretos aos animais, mas também oferecer condições para que possam ter uma vida digna no sentido mais amplo, tendo em vista a integridade física e psicológica para que possam colocar em prática sua autonomia. Direitos asseguram determinadas proteções fundamentais aos animais. Mas assim como a realização da vida de seres humanos vai além do conjunto de direitos que possuem, também as condições para uma vida boa de animais não humanos precisa ir além do conjunto de proteções jurídicas que lhes pode ser assegurado.

Conforme bem pontua Baier (1994, p. 18) em relação aos seres humanos, o direito, e a justiça por eles implicada, é apenas um dos valores a iluminar uma teoria moral e tais noções precisam da presença de outros aspectos a fim de comunicar seu próprio valor. Todos precisamos da linguagem da justiça e dos direitos para modificar a própria posição social, sobretudo, quando se considera o lugar que seres oprimidos ocupam na sociedade, mas isso não é suficiente. Ao se entender a justiça como o respeito aos direitos iguais a bens formais, tais como, a garantia de ter o contrato mantido, o devido processo assegurado, as oportunidades equitativas atestadas, incluindo a oportunidade de participar em atividades políticas que visem a aprovação de políticas e de leis de interesses de grupos, bem como direitos de liberdade de expressão, livre associação e assembleia e de culto religioso, tem-se uma dimensão essencial das relações básicas de cidadania. Todavia, esse não é o único aspecto da vida em sociedade. Conforme destaca Baier: 
[...] nenhum desses bens faz muito para garantir que as pessoas que tem e mutualmente respeitam tais direitos terão algum outro tipo de relacionamento uns com os outros para além do relacionamento mínimo necessário para manter uma tal 'sociedade civil' em funcionamento" (BAIER, 1994, p. 23).

Titulares de direito na sociedade civil podem simplesmente estar sozinhos, tentando suicídio, infelizes no trabalho e apáticas na participação no processo político, ou ainda não encontrar sentido algum em viver. A vida com respeito a direitos pode ser miserável e a causa dessa miséria não é apenas o infortúnio pessoal ou alguma doença psíquica, mas, afirma Baier (1994, p. 23), um empobrecimento moral e social. Trata-se de assumir uma certa postura de nãointerferência com base em direitos como se ela fosse suficiente para respeitar o outro e considerar sua vida moralmente valiosa.

Ao se verificar as considerações de Baier para além de seres humanos, temse que também no caso de animais, direitos jurídicos talvez não sejam suficientes. A inclusão de animais sob a proteção jurídica representa uma forma de cuidado e consideração moral para com eles, mas nossas obrigações morais não ficam restritas ao cumprimento de leis e a tutela jurídica em relação aos animais. Em outros termos, reconhecer direitos aos animais representa uma etapa fundamental da integração de suas vidas dentro da comunidade moral. Porém, os animais sencientes, em muitas situações, necessitam de mais do que direitos para que possam realizar suas formas únicas e singulares de vida de acordo com preferências individuais, isto é, para que as condições de realização de autonomia e liberdade prática estejam presentes.

É nesse sentido que se pode pensar a contribuição da ética do cuidado em relação aos animais não-humanos, isto é, a formação de uma rede de cuidado que vá além da segurança e da tutela jurídicas, tendo em vista assegurar as condições ideais para que animais possam exercer de forma plena e completa sua autonomia prática. Originada em meio à Filosofia Feminista, na década de 80, com a obra de Carol Gilligan, In a Different Voice, a ética do cuidado busca valorizar as relações de cuidado e as implicações de responsabilidade que se formam no contexto dessas relações. De forma complementar à noção de princípios morais, de direitos e de justiça, a ética do cuidado remonta a práticas de atenção às condições específicas de vulnerabilidade do outro, tendo em vista à sustentação de relações de cuidado. Josephine Donovan (1996, p. 163) entende o cuidado como um tipo de "atenção R. Inter. Interdisc. INTERthesis, Florianópolis, v.12, n.1, p.42-64, Jan-Jun. 2015 
amorosa", isto é, um olhar específico, atento e lúcido às particularidades dos seres e à avaliação de suas necessidades. Trata-se de um exercício da imaginação moral, procurando se colocar na condição do outro e apreender sua realidade para desenvolver uma resposta ética adequada com base em seu bem próprio.

A ética do cuidado apresenta-se como uma forma complementar de enriquecimento e valorização social das redes de relações e vínculos de apoio recíproco, fundamentais para os seres, humanos e não humanos, que ao longo de suas vidas podem apresentar momentos de vulnerabilidade mais profundos. Não interferência e respeito à liberdade podem ser suficientes em muitos momentos da vida; porém, em outros, um ambiente de interação, interdependência e interconexão entre pessoas pode ser essencial para a realização dos objetivos individuais, bem como para a condição da própria existência. Muitas dessas relações podem, inclusive, ocorrer entre desiguais, como é o caso de humanos para com não humanos. Isso exige o desenvolvimento de uma sensibilidade para a compreensão da situação específica de vida de muitos animais. Contribuições da ciência são importantes nesse aspecto, mas também a preocupação humana para com o bemestar do outro e de sua forma de vida deve ser incentivada. Baier (1994, p. 23-24) acrescenta que a ética do cuidado, ao pressupor o desenvolvimento da habilidade do cuidar, ensina indivíduos justamente a lidar com as desigualdades e limitações relacionais tendo em vista alcançar ações de cuidado efetivas.

Nesse sentido, um princípio moral do cuidado a ser adotado pelos agentes morais individuais e o Estado é fundamental para proporcionar um cenário que tenha como fim a garantia de vida boa para os animais não humanos. Se o Estado, por meio de políticas públicas, vai além de direitos positivados para garantir que seus cidadãos tenham possibilidades de realização de uma vida plena, o mesmo não pode ser negado aos animais não humanos. Isso adquire especial importância no caso de animais domesticados, os quais, conforme bem pontuam Kymlicka e Donaldson (2011, p. 73-74), foram trazidos para o convívio humano por nós e tornados por nós dependentes para nossos próprios fins. A domesticação exige que repensemos nossas relações com os animais com o intento de torná-las mais justas, afastando as tradicionais práticas de "confinamento coercitivo, manipulação e exploração dos animais para o benefício de seres humanos" (KYMLICKA; DONALDSON, 2011, p. 73). Somos, portanto, responsáveis por lhes oferecer a 
possibilidade de expandirem novamente sua autonomia prática e tornarem-se cada vez mais, menos dependentes de humanos.

A relação que estabelecemos com animais traz, então, implicações em termos de cuidar dos animais para os agentes morais, mas não no sentido estrito de se manter com eles relações de dependência. Ao contrário, o cuidado genuíno para com os animais não humanos toma como prioridade o respeito à autonomia prática de tais seres e sua liberdade de se mover para prover-se. Ainda que a completa independência de tais animais seja talvez inviável - pois esse é um ideal que sequer se aplica aos seres humanos que vivem em sociedade na forma de relações de interdependência permanente - é fundamental que as ações morais tenham em vista a redução de graus de dependência e padrões de interconexão que garantam cada vez mais espaço para o exercício da liberdade específica de animais. Novamente, cabe salientar que não apenas seres humanos individuais se constituem como agentes morais que visam relações de interdependência e interconexão onde haja espaço para a expressão das formas de vida própria de animais, mas ao próprio Estado cabe o desenvolvimento de políticas públicas que tenham tais finalidades em mente.

\section{CONSIDERAÇÕES FINAIS}

Ao longo deste artigo buscou-se apresentar e destacar a importância do conceito de autonomia ou liberdade prática de Steven Wise, tendo em vista a possibilidade de justificar a proteção jurídica de animais não humanos por meio da atribuição de direitos a eles. Ademais, destacou-se que a proteção deve de ir além de direitos jurídicos, incluindo políticas públicas e ações morais guiadas pelo cuidado para que as necessidades e condições particulares de cada animal sejam atendidas. Com isso, é possível, de fato, garantir o respeito à autonomia prática de animais, representada, sobretudo, pela ideia de se mover para o próprio provimento a seu próprio modo e de acordo com o bem da espécie a que pertence.

A concepção de Wise mostrou-se fundamental para se entender a diferença entre os conceitos de autonomia moral tradicional e o de autonomia prática, que pressupõe a existência de diferentes liberdades entre os seres vivos, e, assim, permite incluir os animais não humanos como possuidores dessa nova modalidade 
de autonomia. Ao romper com a tradição kantiana e propor o conceito de liberdade prática enquanto base para reivindicar direitos, o que torna um animal humano ou não humano digno é sua capacidade de mover-se, integrar-se ao meio, alimentar-se, sentir e fazer escolhas dentro das possibilidades e particularidades de sua espécie. Wise defende que seres com as mesmas capacidades práticas tenham os mesmos direitos. Para isso, desenvolve uma tabela de classificação dos tipos de autonomias e liberdades condizentes a cada espécie. Vimos que na classificação da categoria 4 , animais não humanos e humanos encontram-se com as mesmas habilidades.

Por meio das considerações realizadas e tendo por base a noção de autonomia prática, salientou-se que a vida e as relações morais implicam mais do que obrigações legais. Em outras palavras, procurou-se mostrar que garantir as condições para que animais possam mover-se para prover-se a seu próprio modo, ou de acordo com o bem que thes é próprio, pressupõe ir além de certos direitos de proteção positivados. Tanto agentes morais individuais quanto o Estado tem a obrigação de constituírem redes de cuidado que visem assegurar aos animais as condições apropriadas de manifestação de sua espécie. Cabe então ao Estado garantir condições mínimas para que os animais exerçam sua liberdade de forma integral, do mesmo modo que políticas públicas são adotadas para com seres humanos. No caso de animais não humanos, as políticas do Estado devem priorizar medidas de cuidado e proteção que tenham em vista um crescente espaço para o exercício das formas de vida próprias de animais não humanos e a consequente redução de sua dependência em relação a seres humanos.

R. Inter. Interdisc. INTERthesis, Florianópolis, v.12, n.1, p.42-64, Jan-Jun. 2015 


\title{
RIGHTS AND CARE FOR THE PROTECTION OF NONHUMAN ANIMAL'S PRACTICAL AUTONOMY
}

\begin{abstract}
The aim of this paper is to present Steven Wise's concept of practical autonomy and how it is distinguished from the traditional and modern Kantian notion of autonomy. This is justified in order to emphasize the importance of this concept of autonomy for the recognition of legal rights to nonhuman animals, and the protection of its particular way of life through care practices and responsibility in the relations between human and nonhuman animals. By the aid of bibliographical research and theoretical analysis, we foremost present Wise's main conceptual distinctions and, secondly, indicate the application of the concept of practical autonomy in the legal context, aiming to recognize rights for animals. Finally, we show how the concept of practical autonomy requires more than legal rights. It also implies moral obligations by individual agents and by the State to ensure appropriate conditions for autonomy and freedom of nonhuman animals.
\end{abstract}

Keywords: Nonhuman Animals. Autonomy. Care. Rights. Freedom.

\section{DERECHOS Y CUIDADO PARA LA PROTECCIÓN DE LA AUTONOMÍA PRÁCTICA DE LOS ANIMALES NO HUMANOS}

\section{Resumen}

El objetivo del presente artículo es presentar el concepto de autonomía práctica de Steven Wise y el modo cómo éste se distingue de la noción tradicional y moderna de autonomía kantiana, buscando evidenciar la importancia de esa noción de autonomía para el reconocimiento de derechos jurídicos a los animales no humanos y la protección de sus formas específicas de vida por medio de prácticas de cuidado y de responsabilidad en las relaciones entre humanos con no-humanos. Por medio de investigación bibliográfica y análisis teórico, se buscará, inicialmente, presentar las distinciones conceptuales centrales de Wise y, posteriormente, indicar la aplicación del concepto de autonomía práctica en el ámbito jurídico, teniendo en cuenta el reconocimiento de derechos a los animales. Por fin, se muestra cómo el concepto de autonomía práctica requiere más que derechos jurídicos, ya que implica obligaciones morales por parte de agentes individuales y del Estado para asegurar las condiciones adecuadas de autonomía y de libertad de animales no humanos.

Palabras clave: Animales no humanos. Autonomía. Cuidado. Derechos. Libertad. 


\section{REFERÊNCIAS}

BAIER, Annette C. The Need for More than Justice. In: BAIER, Annette C. Moral Prejudices: Essays on Ethics. Cambridge: Harvard University Press, 1994, p. 18-32.

DE WAAL, Frans. The Age of Empathy: Nature's Lessons for a Kinder Society. New York: Three Rivers Press, 2009.

DONALDSON, Sue; KYMLICKA, Will. Zoopolis: A Political Theory of Animal Rights. Oxford: Oxford University Press, 2011.

DONOVAN, Josephine. Attention to Suffering: Sympathy as a Basis for Ethical Treatment of Animals. In: DONOVAN, Josephine; ADAMS, Carol (Eds). Beyond Animal Rights: A Feminist Caring Ethic for the Treatment of Animals. New York: Continuum, 1996, p. 147-169.

FELIPE, Sônia. Ética e experimentação Animal: fundamentos abolicionistas. Florianópolis: Editora da UFSC, 2007.

FRANCIONE, Gary. Introdução aos direitos animais: seu filho ou cachorro? Trad. Regina Rheda. Campinas, SP: Editora da Unicamp, 2013.

GILLIGAN, Carol. In a Different Voice: Psychological Theory and Women's Development. Cambridge: Harvard University Press, 1982.

KANT, Immanuel. Fundamentação da metafísica dos costumes. Trad. Paulo Quintela. Lisboa: Edições 70, 1986.

SINGER, Peter. Ética Prática. 3. ed. Trad. Jeferson Luiz Camargo. São Paulo: Martins Fonte, 2002.

TAYLOR, Paul. Respect for Nature: a Theory of Environmental Ethics. Princeton: Princeton University Press, 1989. 
WISE, Steven, M. Drawing the line: science and the case for animal rights.

Cambridge, MA: Perseus Books, 2002.

Artigo:

Submetido em 04.05.2015

Aceito em 03.06.2015

R. Inter. Interdisc. INTERthesis, Florianópolis, v.12, n.1, p.42-64, Jan-Jun. 2015 